\title{
Attitudes of Students in Jordanian Public Secondary Schools towards Online Exams during the Coronavirus Crisis and the Impact of Such Exams on Motivation
}

\author{
Mohammad Rafe’ Naser Dahadhah $\quad$ Ra’ed Ali Kareem Al-Hamoori
}

\begin{abstract}
The present study aimed to explore the attitudes of students in Jordanian public secondary schools towards online exams during the Coronavirus crisis. It aimed to explore the impact of such exams on students' motivation. A descriptive analytical approach was adopted. The researchers selected a purposive sample that consists from 300 $11^{\text {th }}$ grade female and male students. Those students were selected from 10 public secondary schools located in Amman, Jordan. Questionnaire forms were distributed to those students online. However, 292 forms were retrieved and considered valid for analysis. Descriptive statistical methods and the SPSS program were used. Several findings were reached. For instance, respondents have positive attitudes towards online exams. Online exams enable teachers to track students' progress and develop students' problem solving skills. In addition, they positively affect students' motivation to study and show the best possible achievement.
\end{abstract}

Keywords: Attitudes, assessment, online exams, motivation, Jordan.

DOI: $10.7176 / \mathrm{JEP} / 11-27-12$

Publication date:September $30^{\text {th }} 2020$

\section{Introduction:}

Assessment refers to the process through which one's knowledge, capability, understanding, or skill is measured (Sorensen, 2013). It plays a crucial role in improving the learning process. That is because assessment provides learners with feedback. Such feedback enables learners to improve their performance (Nicol, 2007). Assessment is important in the educational process because it identifies the degree to which the educational objectives have been met. It is important in the educational process because it identifies the degree to which educational institutions meet the needs of the members of the society (Shah, 2002).

Due to the major development of ICTs, many educational institutions worldwide started to use online exams for assessing students' achievement instead of using paper-based exams. Online exam refers to the exams taken through using the internet (Ayo et al., 2007, p. 126). It may be taken through using a learning management system (Sorensen, 2013). It may include multiple choice, true/false, matching, short answer or calculation questions (AlQdah and Ababneh, 2017). It may include: fill in the blank, categorization, re-ordering items, and drag and drop questions (Singh \& De Villiers, 2017). It is suitable for assessing the students who suffer from a disability. For instance, the examinees who suffer from visual impairments may change the font size of the online exam sheet in order to read the questions independently (Amer, 2020).

Online exams have two types. The first type is the linear exam. Through the latter exam, the questions shall be presented in a specific order without taking into consideration the examinee's performance on the exam. The second type is the adaptive exam. Through the adaptive exam, the questions shall be ordered based on the examinee's performance on the exam (Ajinaja, 2017). Many students prefer online exams due to the merits they provide. For instance, online exam provides students with instant feedback once they finish taking the exam. It hinders students from cheating. That is because the instructor can use various forms of exams. In addition, online exams enable students to save time. That is because online exams require to study less for the exam (Al-Qdah and Ababneh, 2017).

Online exams are considered less tiring, because students won't have to write full interpretation for their answer (Al-Qdah and Ababneh, 2017). They play a significant role in measuring students' amount of knowledge and the degree to which the students have mastered a specific skill. They are suitable for assessing students of various learning styles. For instance, there are visual, auditory and reading/writing learners (Jamil, 2012)

During the academic year (2019/2020), Jordan suffered from the Coronavirus. Hence, the Jordanian government decided to provide students in higher education institutions and schools with distance education instead of face-to-face education. That was decided to protect the health of students. Regarding school education, it was delivered through using Darsak (i.e. an online platform) and TV channels (The United Nations Children's Fund is a United Nations, 2020). During this process, school students in Jordan were assessed through using online exams. In this regard, the researchers of the present study believe that it's necessary to conduct studies that assess students' experience during this crisis in terms of learning outcomes, assessment and social aspects. That shall contribute to improving the quality of education in Jordan.

It has been suggested that students' attitudes towards online exams shall affect their academic achievement (Al- Khayat, 2017). Hence, it's significant to explore the attitudes of students towards this type of the exam. That 
shall positively affect the outcomes of academic institutions. Therefore, the researchers of the present study aimed to explore the attitudes of students in Jordanian public secondary schools towards online exams during the Coronavirus crisis. They aimed to explore the impact of such attitudes on motivation.

\section{Objectives:}

The researchers aimed at

a)- Identifying the attitudes of students in Jordanian public secondary schools towards online exams during the Coronavirus crisis.

b)- Identifying the impact of using online exams on the motivation of students in Jordanian public secondary schools

\section{Questions:}

The researchers aimed at answering the questions below

Q.1. What are the attitudes of students in Jordanian public secondary schools towards online exams during the Coronavirus crisis?

Q.2. What is the impact of using online exams on the motivation of students in Jordanian public secondary schools?

\section{Significance of the Study}

The present study is significant due to the reasons shown below:

a. There isn't any research that sheds a light on the perceptions of students in Jordanian public secondary schools towards online exams during the Coronavirus crisis. Hence, the present research contributes to filling a gap in the relevant literature.

b. The results of the present study enables decision makers at the Jordanian Ministry of Education to take effective decisions that improve the quality of assessment in Jordanian schools.

c. The results of the present study enables the developers of the curricula guides in Jordan to decide whether to integrate models of online quizzes or not.

\section{Limits:}

The present study was conducted during the second semester of the academic year (2019/2020). It was conducted in 10 public secondary schools located in Amman, Jordan.

\section{Definition of Terms}

\subsection{Theoretical definitions}

- $\quad$ Attitude: It stands for any evaluative judgment. This judgment identifies the extent of preferring a specific individual, or item (Crano and Prislin, 2006, p.347).

Online exam: It refers to the exam taken through using the internet (Ayo et al., 2007, p. 126). It may be taken through using a learning management system (Sorensen, 2013). It may include multiple choice, true/false, matching, short answer or calculation questions (Al-Qdah and Ababneh, 2017). It may include: fill in the blank, categorization, re-ordering items, and drag and drop questions (Singh \& De Villiers, 2017).

Motivation: It refers to the process that involves initiating, guiding, and maintaining a goal-oriented behaviour. It drives one to act. It involves social, emotional, cognitive and biological aspects (Goyal, 2015)

\subsection{Operational definitions:}

- $\quad$ Attitude: It refers to the attitude of the students in Jordanian public secondary schools towards online exams during the Coronavirus crisis.

Online exams: They refer to the exams taken at home by the students enrolled in Jordanian public secondary schools through using the web during the Coronavirus crisis.

- $\quad$ Motivation: It refers to the motivation of students in Jordanian public secondary schools to show a better performance and study hard when having an online exam during the Coronavirus crisis

\section{Theoretical framework}

Online exams have many merits and benefits. For instance, they enable students to concentrate more due to the way in which the questions are presented. They are a flexible and convenient mean for assessing students, because students don't have to write through pen nor erase their answers. It's because students can take the online exam at any place and time (Chin et al. 1990). Online exams enable students to show a better academic achievement (Mazzeo et al., 1992). They are considered more objective than the paper-based exams in assessing the students' performance. That is because computers don't take into consideration the culture or race of the students when correcting (Ozden et al., 2004).

Online exams motivate students to learn. They motivate and encourage students to practice the skills they 
have learnt. They are considered an assessment mean of low cost (Ozden et al., 2004). According to Bodmann and Robinson (2004), online exams don't enable students to show a better academic achievement. However, taking online exams requires less time than taking paper-based exams (Bodmann and Robinson, 2004).

Online exams enable educators to assess the life skills of students. That is because online exams can display simulation models that simulate situations faced in real life. It should be noted that online exams play a significant role in motivating students to learn and show a better performance. They make learners feel that they are in control over their learning process (Ridgway et al., 2004). They enable instructors to track students' progress and manage the collected data efficiently. Such data may include: the student's marks, names, grades, and etc.. (Hamilton \& Shoen, 2005).

Online exams are a flexible mean of assessment, because students can take such exams at any place and time. It's because students are provided with feedback instantly once they finish (James, 2016). They enable teachers to save the time needed for correcting exam papers. They motivate students to engage more in the teaching-learning process (Dermo, 2009). They reduce the costs of printing question sheets (Rastgoo et al., 2010).

Online exams enable educators to determine the problems, weaknesses and learning needs of their students. They offer students feedback instantly once they finish. Through using online exams, educational institutions can have numerous exams stored and organized for various courses (Nikolova, 2012). Online exams promote deep learning and develop the problem solving skills of the targeted learners (Sorensen, 2013). They can assess the exact amount of knowledge that the learners have about the targeted material (Petrisor et al., 2016).

Online exams enable students to show more productivity on the exam and answer a greater number of questions within the specified time. They enable instructors to use various formats and designs (Ajinaja, 2017). They enable academic institutions and educators to assess hundreds and thousands of students within a short time. Academic institutions and educators can use online exams to assess the students living in remote places without forcing them to travel and pay the costs associated with accommodation and travelling. It's suggested that online exams serve as a secure assessment method because each student has his own password and username that he/she must enter to take the exam (Alruwais et al., 2018).

\section{Empirical Studies}

Nikou and Economides (2016) aimed at identifying the influence of computer-based, mobile-based and paperbased assessments on the motivation and achievement levels of secondary school students in physics. An experimental approach was adopted. The latter scholars administered pre-test and post-test to meet the intended goals. They concluded that the computer-based and mobile-based assessment have a positive impact on the academic achievement level of the students of poor achievement. It was found that computer-based and mobilebased assessments have a positive impact on one's motivation to learn and acquire knowledge.

Al-Omari and Eyadat (2016) aimed to explore the attitudes of students and instructors at Yarmook University towards computerized tests. The sample consists from 120 instructors and 380 university students. Those instructors and students were selected through using the random stratified sampling technique. A twenty-seven item questionnaire was developed. From the students' view, the score gained through the paper-bases exams is more reliable than the score gained through the computerized exams. Computerized exams can be used in all courses. They provide instructors and students with feedback. They enable instructors to take the individual differences between students into consideration. Students have moderate attitudes towards the role of computerized exams in promoting creativity. They have moderate attitudes towards the confidentiality of computerized exams. They have moderate attitudes towards the role of these exams in saving the efforts and time of students and instructors (Al-Omari and Eyadat, 2016).

From the instructors' perspective, computerized exams reduce the stress and fear associated with the assessment process. Instructors show moderate attitudes towards the role computerized exams in motivating students to study for the exam. They show moderate attitudes towards the role computerized exams in motivating student to learn and acquire more knowledge. Computerized exams are associated with lower number of cheating opportunities than paper-based exams. They show moderate attitudes towards the complexity of the software used for taking such exams. They believe that there isn't any need for providing students with prior training about the way of using the examination software (Al-Omari and Eyadat, 2016).

Al-Juda (2017) aimed at exploring the perceptions of instructors at Tabuk University towards online exams. A twenty-item questionnaire was utilized for collecting data from 100 instructors. Those instructors were selected purposively. A descriptive analytical approach was adopted. It was found that online exams save the time and effort of instructors. Administering online exams makes students believe in themselves and capabilities. Online exams make the assessment process an interesting process. However, students must be provided with prior training about the way of using the examination software. Instructors prefer using online exams because such exams offer immediate feedback (Al-Juda, 2017).

Alsadoon (2017) aimed at identifying the perceptions of the students enrolled in the Saudi Electronic University towards e-assessment. He used a survey consisting from 15 items. The survey forms were passed to 80 
students through using email. However, 44 forms were retrieved and processed statistically. The respondents show positive attitudes in this regard. They prefer e-exams over the paper-based ones. E-exams contribute to enhancing the quality of provided education. They are considered an objective mean for assessment. They reduce the stress that students may experience during the assessment process. They improve the technical skills of students and promotes a self-learning approach among learners. They hinder the examinees from cheating. They serve as a suitable mean for assessing all students. They enable instructors to display a variety of questions.. However, they aren't suitable for all courses.

Susan et al. (2018) aimed at identifying the attitudes of students in Nigerian universities towards administering computer-based exams. The sample consists form 500 students enrolled at Nigerian universities. Questionnaire forms were distributed to them. 400 forms were retrieved and analysed. The respondents show positive attitudes in this regard. The computer-based exams serve as a secure assessment method. They enable learners to edit their answers. The respondents don't face technical problems when logging into the examinations system nor opening the software.

Shraim (2018) aimed to explore the perceptions of students in higher education institutions in Palestine towards online exams. A survey was used. The survey forms were used for collecting data from 342 undergraduates enrolled in Palestine Technical University-Kadoorie. It was found that students have positive attitudes towards such exams. Such exams are considered more efficient than paper-based exams, because they save the time, money, and effort associated with the assessment process. They don't reduce the anxiety and stress associated with the assessment process. They are effective for preventing plagiarism and cheating. The marking process in the e-exam is more accurate than the counterpart process of the paper-based exam. Online exam aren't suitable for any course. They aren't capable of testing the learner's exact amount of knowledge. Paper-based exams are associated with more security than online exams

Al-Momani (2019) aimed to explore the undergraduate students' attitudes in Jordan towards administering eexams in Jordan. She developed a questionnaire for data collection. She distributed 93 questionnaire forms to undergraduate students who were enrolled at the University of Jordan. All the forms were retrieved. 87 forms are valid for analysis. The latter scholar found that administering e-exams makes students feel less stressed than administering paper-based exams. In addition, e-exams make students show a higher level of concentration. They contribute to the development of the cognitive skills of learners. They don't facilitate cheating.. Taking e-exam requires less time than taking paper-based exams. E-exams are effective for assessing a student's amount of knowledge. However, they aren't effective for assessing one's skills. They aren't suitable for all courses. They don't contribute to saving costs in academic institutions.

Amer (2020) aimed to explore the effectiveness of employing electronic exams in assessing the students enrolled at Saudi universities. He aimed to assess that from the perspective of those students. He developed a five point Likert questionnaire. A purposive sample was selected. It consists from 370 male and female students enrolled at Prince Sattam bin Abed Al-Aziz University in Saudi Arabia. Questionnaire forms were distributed to those students and retrieved. 357 forms were considered valid for analysis. The SPSS program was used. It was found that electronic exams are very effective in assessing students. In addition, electronic exams motivate students to show the best possible performance. They improve the learner's abilities to manage his/her time while taking the exam. They serve as an objective mean for assessment. They enable students to answer questions faster. They enable instructors to track the progress achieved by each learner. They make the cheating difficult for students. However, they aren't a secure assessment method. The preparation for e-exam requires exerting more effort than preparing for paper-based exams.

\section{Methodology:}

9.1. Approach

A descriptive analytical approach was adopted.

9.2. Instrument

The researchers used a five point Likert questionnaire that consists from a cover page and two parts. The cover page identifies the goals behind collecting data through the questionnaire. The first part collects data about the respondents' attitudes towards online exams during the Coronavirus crisis. It consists from 12 items. The second part collects data about the impact of using online exams on motivation. It consists from 2 items. The questionnaire was developed based on the studies of the following researchers: Nikou and Economides (2016), Al-Omari and Eyadat (2016), Amer (2020), Shraim (2018), Nikolova (2012), Chin et al. (1990), Hamilton \& Shoen (2005), Sorensen (2013), Al-Momani (2019), Rastgoo et al. (2010) and Alsadoon (2017).

9.3. Sample and Population

The population is represented in all the students who were enrolled in the Jordanian public secondary schools during the academic year $(2019 / 2020)$. The researchers selected a purposive sample that consists from $30011^{\text {th }}$ grade female and male students. Those students were selected from 10 public secondary schools located in Amman, Jordan. Questionnaire forms were distributed to these students online in Arabic language. However, 292 forms 
were retrieved and considered valid for analysis. The response rate is $97.33 \%$. Data about the respondents is presented below:

Table (1): The distribution of the respondents in accordance with gender and computer skills

\begin{tabular}{|l|l|l|l|}
\hline Variable & Category & Frequency & Percentage \\
\hline \multirow{3}{*}{ Gender } & Male & 156 & 53.42 \\
\cline { 2 - 4 } & Female & 136 & 46.57 \\
\hline \multirow{5}{*}{ Computer skills } & Excellent & 56 & 19.17 \\
\cline { 2 - 4 } & very good & 141 & 48.28 \\
\cline { 2 - 4 } & Good & 48 & 16.43 \\
\cline { 2 - 4 } & Fair & 22 & 7.534 \\
\cline { 2 - 4 } & Poor & 25 & 8.56 \\
\hline
\end{tabular}

$\mathrm{N}=292$

$53.42 \%$ of the students are males and $46.57 \%$ of the students are females. $19.17 \%$ of the students have excellent computer skills and $48.28 \%$ of the students have very good skills in this regard. In addition, $16.43 \%$ of the students possess good skills in this regard and $7.53 \%$ of the students have fair skills. $8.56 \%$ of the students have poor skills. These percentages indicate that Jordanian secondary public schools provide much attention to the development of the students' computer skills.

\subsection{Validity of the Instrument}

The researchers passed the initial version of the questionnaire to 3 faculty members to provide an assessment for the latter version in terms of language, clarity, and relevancy. Those experts are specialized in educational sciences and work at well-known Jordanian universities. The latter version was passed in Arabic language to the experts. All the experts suggested that the questionnaire is clear, and doesn't include language mistakes. They suggested that the items are relevant to the goals of the study. However, one faculty member suggested adding two items which were added. The final version was drafted and translated into English language to be presented in this research.

\subsection{Reliability of the Instrument}

To measure such reliability, the Cronbach alpha coefficient value was calculated. It's 0.833 which means that the instrument is highly reliable and capable of meeting the intended goals.

\subsection{Methods and Criteria for Data analysis}

The researchers used descriptive statistical methods. They also used the SPSS software. The descriptive statistical methods in this study include: percentages, frequencies, standard deviations and means.

For classifying means, the criteria shown below were adopted by the researchers.

Table (2): The criteria used for the classification of means

\begin{tabular}{|l|l|l|}
\hline Range & Level & Attitude \\
\hline 2.33 or less & Low & Negative attitude \\
\hline $2.34-3.66$ & Moderate & Neutral attitude \\
\hline 3.67 or more & High & Positive attitude \\
\hline
\end{tabular}

*Source: Aljbour (2020)

The five point Likert scale consists from 5 rating categories. Those categories are shown below Table (3): The categories and scores of the five point Likert scale

*Source: Aljbour (2020)

\begin{tabular}{|l|l|}
\hline Category & Score \\
\hline Strongly agree & 5 \\
\hline Agree & 4 \\
\hline Neutral & 3 \\
\hline Disagree & 2 \\
\hline Strongly disagree & 1 \\
\hline
\end{tabular}

\section{Discussion and results}

10.1. Discussion and results related to the first question:

Q.1. What are the attitudes of students in Jordanian public secondary schools towards online exams during the Coronavirus crisis? 
Table (4): The respondents' attitudes of students in Jordanian public secondary schools towards online exams during the Coronavirus crisis

\begin{tabular}{|l|l|l|l|l|l|}
\hline No. & Statement & Mean & Std. & Level & Attitude \\
\hline 1. & $\begin{array}{l}\text { Online exams are more objective than the paper-based exams } \\
\text { in assessing the students' performance }\end{array}$ & 4.81 & 0.47 & High & Positive \\
\hline 2. & Online exams reduce the costs associated with assessment & 4.93 & 0.60 & High & Positive \\
\hline 3. & $\begin{array}{l}\text { Online exams enable educators to assess the skills of } \\
\text { students. }\end{array}$ & 2.10 & 0.22 & Low & Negative \\
\hline 4. & Online exams enable teachers to track the students' progress & 4.57 & 0.19 & High & Positive \\
\hline 5. & Online exams develop the problem solving skills of students & 4.84 & 0.56 & High & Positive \\
\hline 6. & Online exams offer more security than paper-based exams. & 1.77 & 0.78 & Low & Negative \\
\hline 7. & Online exam is a flexible mean for assessment & 4.95 & 0.26 & High & Positive \\
\hline 8. & $\begin{array}{l}\text { Online exams enable educators to determine the exact } \\
\text { learning needs of their students. }\end{array}$ & 1.62 & 0.40 & Low & Negative \\
\hline 9. & Educators can use online exams for assessment in all courses & 1.54 & 0.35 & Low & Negative \\
\hline 10. & $\begin{array}{l}\text { Online exams contribute to reducing the stress associated } \\
\text { with the assessment process. }\end{array}$ & 4.73 & 0.56 & High & Positive \\
\hline 11. & $\begin{array}{l}\text { Online exams improve the student's ability to manage his/her } \\
\text { time during the exam }\end{array}$ & 4.26 & 0.84 & High & Positive \\
\hline 12. & $\begin{array}{l}\text { Online exams contribute to promoting creativity among } \\
\text { students }\end{array}$ & 4.58 & 0.81 & High & Positive \\
\hline & Total & 3.72 & 0.50 & High & Positive \\
\hline
\end{tabular}

Based on table (4), respondents have positive attitudes towards using online exams during the Coronavirus crisis, because the overall mean is 3.72. The latter result is consistent with the result concluded by Shraim (2018). It may be attributed to the fact that young students like using technology in the learning and assessment processes. It was found that online exams are more objective than the paper-based exams in assessing the students' performance levels, because the relevant mean is 4.81 . The latter result is consistent with the result concluded by Alsadoon (2017). It may be attributed to the fact that online exams employ the auto-correction feature. Thus, student's race or culture shall not affect his/her grade.

Online exams reduce the costs associated with the assessment process, because the relevant mean is 4.93. The latter result is consistent with what is suggested by Rastgoo et al. (2010). It may be attributed to the fact that online exams save the costs associated with printing the question sheets. It was found that online exams don't enable educators to assess the skills of students, because the relevant mean is 2.10. The latter result is consistent with the result concluded by Al-Momani (2019). It may be attributed to the fact that assessing certain skills (e.g. physical and musical skills) requires having practical assessments.

Online exams enable teachers to track students' progress, because the relevant mean is 4.57. The latter result is consistent with the result concluded by Hamilton \& Shoen (2005). It may be attributed to the fact that students' marks shall be automatically saved to the computer system when using the online exams. That shall facilitate the process of comparing student's current mark with the previous marks. It was found that online exams develop the problem solving skills of students, because the relevant mean is 4.84 . The latter result is consistent with the result concluded by Sorensen (2013). It may be attributed to the fact that online exams include multimedia and simulations models which develop the capability of students to solve problems and imagine possible solutions.

Online exams don't offer more security than paper-based exams, because the relevant mean is 1.77 . The latter result is consistent with the result concluded by Shraim (2018). It may be attributed to the fact that the scores saved through online exams may be hacked by hackers. That may lead to the loss or change of data. It was found that online exam is a flexible mean for assessment, because the relevant mean is 4.95. The latter result is consistent with the result concluded by Chin et al. (1990). It may be attributed to the fact that online exams can be taken at any time and place.

Online exams don't enable educators to determine the exact learning needs of their students, because the relevant mean is 1.62 . The latter result is inconsistent with the result concluded by Nikolova (2012). It may be attributed to the fact that online exams don't provide students with opportunities to interpret their answers. It was found that educators can't use online exams for assessment in all courses, because the relevant mean is 1.54 . The latter result is inconsistent with the result concluded by Al-Omari and Eyadat (2016). It may be attributed to the fact that educators in some courses (e.g. music course) need to use practical assessment methods for assessing students' knowledge and skills.

Online exams contribute to reducing the stress associated with the assessment process, because the relevant mean is 4.73. The latter result is consistent with the result concluded by Shraim (2018). It may be attributed to the fact that online exams provide the student with the ability to edit his/her answers fast without having to waste time 
erasing the answer and writing a new one. It was found that online exams improve the student's ability to manage his/her time during the exam, because the relevant mean is 4.26. The latter result is consistent with the result concluded by Amer (2020). It may be attributed to the fact that online exams enable the examinee to see the time that has passed and the time left. That shall enable students to divide the duration of the exam efficiently in accordance with the number of questions. It was found that online exams contribute to promoting creativity, because the relevant mean is 4.58. The latter result is consistent with the result concluded by Al-Omari and Eyadat (2016). It may be attributed to the fact that online exams employ visual and auditory multimedia that develop students' capability to come up with innovative ideas.

10.2. Discussion and results related to the second question:

Q.2. What is the impact of using online exams on the motivation of students in Jordanian public secondary schools? Table (5): The impact of using online exams on the motivation of students in Jordanian public secondary schools

\begin{tabular}{|l|l|l|l|l|l|}
\hline No. & Statement & Mean & Std. & Level & Attitude \\
\hline 1. & $\begin{array}{l}\text { Having an online exams makes feel more motivated to } \\
\text { study than having a paper-based exam }\end{array}$ & 4.76 & 0.31 & High & Positive \\
\hline 2. & $\begin{array}{l}\text { Online exams motivate me to show the best possible } \\
\text { achievement }\end{array}$ & 4.85 & 0.26 & High & Positive \\
\hline & Total & 4.80 & 0.28 & High & Positive \\
\hline
\end{tabular}

Based on table (5), online exams have a positive impact on students' motivation, because the overall mean is 4.80. The latter result is consistent with the result concluded by Nikou and Economides (2016). It was found that having an online exam shall make students feel more motivated to study than having a paper-based exams. That was concluded because the relevant mean is 4.76 . That may be attributed to the fact that respondents prefers using technology. It was found that online exams motivate students to show the best possible achievement. That was concluded because the relevant mean is 4.85 . The results in this regard may be attributed to the fact that the use of multimedia and the format of online exams attract students to the learning and assessment process. They may be attributed to the fact that students enjoy having control over their own learning process.

\section{Conclusion:}

It was found that online exams positively affect students' motivation in Jordanian public secondary schools. For instance, online exams positive affect those students' motivation to study and show the best performance. Hence, online quizzes should be used for assessing low achievers to motivate them to show a better performance. It was found that students in Jordanian public secondary schools have positive attitudes towards the use of online exams during the Coronavirus crisis. Hence, online exams should be used in the future in Jordanian public secondary schools along with paper-based exams.

It was found that online assessment are objective due to the auto-correction feature. In addition, it was found that such exams reduce the costs associated with assessment. Hence, such exams can be used by the educational and training institutions experiencing poor financial conditions. In addition, they enable teachers to track students' progress. That shall enable teachers to provide parents with detailed information and reports about the academic achievement and progress of their sons/ daughters.

\section{Recommendations:}

The researchers recommend the following:

a. Using online exams for assessing students in Jordanian public secondary schools along with paper-based exams

b. Adding online quizzes to the guides of secondary school curricula in Jordan.

c. Conducting studies about the effectiveness of using online exams in the computer labs of primary schools in Jordan.

d. Providing Jordanian private and public school teachers and students with training courses about the way of using online platforms and managing e-data efficiently. That shall enable those schools to deliver education of high quality during any crisis.

\section{Acknowledgement}

The researchers would like to thank the Ministry of Education in Jordan for taking effective measures during the Coronavirus crisis.

\section{References:}

Ajinaja, M. (2017). The design and implementation of a computer based testing system using component-based software engineering. International Journal of Computer Science and Telecommunications, 8(1), 58-65.

Aljbour, H. (2020). The extent of practicing ethical leadership by public secondary school principals in Amman. 
Journal of Education and Practice. 11(15). 57-63, DOI: 10.7176/JEP/11-15-07

Al-Juda, M. (2017). Trends faculty members toward an online exams and constraints applied at the University of Tabuk. The International Interdisciplinary Journal of Education. 6(2). $\quad$ pp. 77-87, http://search.shamaa.org/FullRecord?ID=116968

Al- Khayat, M. (2017). Students and instructors' attitudes toward computerized tests in business faculty at the main campus of Al- Blaqa Applied University. The Journal of Al-Najah University for Research (human sciences). 31(11).

Al-Momani, O. (2019). The attitudes of undergraduate students towards using e-exams for assessment in Jordan, British Journal of Education, 7(9), pp.14-28

Al-Omari, M.; and Eyadat, Y. (2016). The perceptions of faculty members and students on the effectiveness of computerized tests in the teaching and learning process at Yarmouk University. The Jordanian Journal for Educational Sciences. 12(4). pp. 478 - 469

Al-Qdah, M.; and Ababneh, I. ((2017). Comparing online and paper exams: Performances and perceptions of Saudi students. International Journal of Information and Education Technology, 7(2).

Alruwais, N., Wills, G., \& Wald, M. (2018). Advantages and challenges of using e-assessment. International Journal of Information and Education Technology, 8(1), 34-37.Available at: https://doi.org/10.18178/ijiet.2018.8.1.1008.

Alsadoon, H. (2017). Students' perceptions of e-assessment at Saudi Electronic University. The Turkish Online Journal of Educational Technology (TOJET), 16(1). p. 147-153

Amer, M. (2020). Effectiveness of using electronic exams in assessment in Saudi universities: Empirical Study. International Journal of Educational Technology and Learning, 8(2), pp. 61-69. DOI: 10.20448/2003.82.61.69

Ayo, C. K., Akinyemi, I. O.; Adebiyi, A. A. \& Ekong, U. O. (2007). The prospects of e-examination implementation in Nigeria. Turkish Online Journal of Distance Education, 8(4), p. 125-134

Bodmann, S. M. and Robinson, D. H. (2004). Speed and performance differences among computer-based and paper-pencil tests. Journal of Educational Computing Research, 31(1), p. $51-60$.

Chin, C. (1990). Effects of computer-based tests on the achievement, anxiety, and attitudes of grade 10 science students. Published MA thesis. The University of British Columbia. British Columbia. Canada

Crano, W. D., \& Prislin, R. (2006). Attitudes and persuasion. Annual Review of Psychology, Vol. 57, p. 345 - 374 , https://doi.org/10.1146/annurev.psych.57.102904.190034

Dermo, J. (2009). E-Assessment and the student learning experience: A survey of student perceptions of eassessment. British Journal of Educational Technology, 40 (2), 203-214

Goyal, P. (2015). Motivation: concept, theories and practical implications. International Research Journal of Commerce, Arts and Science, 6(8), p.71-78

Hamilton, D. \& Shoen, E. (2005). Same song, second verse: evaluation and improvement of an established assessment program. In K. Martell \& T. Calderon, Assessment of student learning in business schools: Best practices each step of the way. Tallahassee, Florida, USA: The Association for Institutional Research

James, R.(2016). Tertiary student attitudes to invigilated, online summative examinations. International Journal of Educational Technology in Higher Education, 13(19), 1-13

Jamil, M., Tariq, R. H., \& Shami, P. A. (2012). Computer-based vs paper-based examinations: Perceptions of university teachers. Turkish Online Journal of Educational Technology, 11(4), 371-381.

Mazzeo, J.; Druesne, B.; Raffeld, P.; Checketts, K.; Muhlstein, A. (1992). Comparability of computer and paperand-pencil scores for two CLEP general examinations, ETS Research Report Series. Issue No. 1. Retrieved from: https://doi.org/10.1002/j.2333-8504.1992.tb01446.x

Nicol, D. (2007). Laying a foundation for lifelong learning: case studies of e-assessment in large 1st-year classes. British Journal of Educational Technology, 38 (4): 668-678

Nikou, S. A., \& Economides, A. A. (2016). The impact of paper-based, computer-based and mobile-based selfassessment on students' science motivation and achievement. Computers in Human Behavior, 55, 12411248.Available at: https://doi.org/10.1016/j.chb.2015.09.025

Nikolova, M. (2012). Characteristics and forms of the electronic assessment of the knowledge. The Journal of the Research Works of the University of Ruse, 51(6), 93- 98.

Ozden, Y., Erturk, I. \& Sanli, R.(2004). Students' perceptions of online assessment: A case study. Journal of Distance Education, 19 (2), 77-92.

Petrisor, M., Marusteri, M., Simpalean, D., Carasca, E., \& Ghiga, D. (2016). Medical students' acceptance of online assessment systems. Acta Medica Marisiensis, 62(1), 30-32

Rastgoo, A., Namvar, Y. \& Iran, A. (2010). Assessment Approach in virtual learning. Turkish Online Journal of Distance Education TOJDE, 11 (1). ISSN 1302-6488

Ridgway, J., McCusker, S., \& Pead, D. (2004). Literature review of e-assessment. Bristol: UNSPECIFIED. Future $\mathrm{Lab}$ 
Rostaminezhad, M. (2019). Students' perceptions of the strengths and limitations of electronic tests focusing on instant feedback. Journal of information technology Education Research. VOl. 18

Shah, J. (2002). Validity and credibility of public examinations in Pakistan, Published MA thesis. Islamia University Bahawalpur, Pakistan.

Shraim, K. (2018). Online examination practices in higher education institutions: Learners' perspective. Turkish Online Journal of Distance Education-TOJDE, 20(4), pp.185-196

Singh, U. G., \& De Villiers, M. R. (2017). An evaluation framework and instrument for evaluating e-assessment tools. The International Review of Research in Open and Distributed Learning, 18(6), 164-185.Available at: https://doi.org/10.19173/irrodl.v18i6.2804.

Sorensen, E. (2013). Implementation and student perceptions of e-assessment in a Chemical Engineering module. European Journal of Engineering Education, 38(2), 172-185

Susan, K.; IsauAdewole, A., Olugbenga, A., and Olusegun, A. (2018). Students' perception of computer-based examinations: A case study of Ladoke Akintola University of Technology, Ogbomoso Oyo State, Nigeria. Journal of Humanities and Social Science, 23(5), 1-7.

The United Nations Children's Fund is a United Nations (UNICEF). (2020). UNICEF and the COVID-19 response for education in Jordan: One month on 